\title{
AFTERIMAGES
}

JONATHAN WIRTSCHAFTER, EDITOR

\section{Unexplained Heterochromia. Intraocular Foreign Body Demonstrated by Computed Tomography}

\author{
CHARLES C. BARR, M.D., ANDREW K. VINE, M.D., AND CSABA L. MARTONYI, F.O.P.S.
}

W.K. Kellogg Eye Center, University of Michigan, Ann Arbor. Michigan

\begin{abstract}
Standard radiographic techniques are often inadequate in demonstrating the presence and location of intraocular foreign bodies. Computerized axial tomography was used to confirm the presence of a metallic foreign body in a patient with heterochromia iridis and suspected ocular siderosis in whom no foreign material was found by conventional examination methods.
\end{abstract}

(Surv Ophthalmol 28:409-4l1, 1984)

Key words. computerized axial tomography - heterochromia • intraocular foreign body - siderosis

1: n the past, ophthalmologists have often had difficulty in determining the exact location of foreign bodies in the globe and orbit. The following case description and photographs demonstrate the value of newer diagnostic techniques, specifically, computerized axial tomography.

\section{Case Report}

The patient was a 24-year-old male who was noted to have a dilated left pupil on routine ophthalmic examination. His past history was significant in that he had attempted suicide with a rifle blast to the head four years previously; numerous metallic fragments were embedded extracranially in the right parietal region. Five months prior to examination, the patient had been treated for a corneal abrasion in the left eye that resulted from striking metal on metal.

At initial examination, the vision was $6 / 6$ OU. The left pupil was dilated to $7 \mathrm{~mm}$ and had a sluggish response to light. Heterochromia of the iris was present (Fig. I). A full thickness corneal scar was noted superotemporally in the left eye. The intraocular pressure was normal in both eyes.

Ocular siderosis from an iron containing foreign body was suspected, but gonioscopy and dilated funduscopic examination with scleral depression failed to reveal a foreign body. The electroretinogram was normal in both eyes. Orbital $\mathrm{x}$-rays were obtained; no foreign body was detected (Fig. 2).

Computerized axial tomography of the orbits demonstrated a small, metallic density foreign body in the region of the pars plicata in the six o'clock meridian of the left eye (Fig. 3). This foreign body was subsequently removed by magnetic extraction. The patient maintained his good visual acuity postoperatively.

\section{Discussion}

It is well recognized that standard radiographic techniques and sonography have limitations in de- 

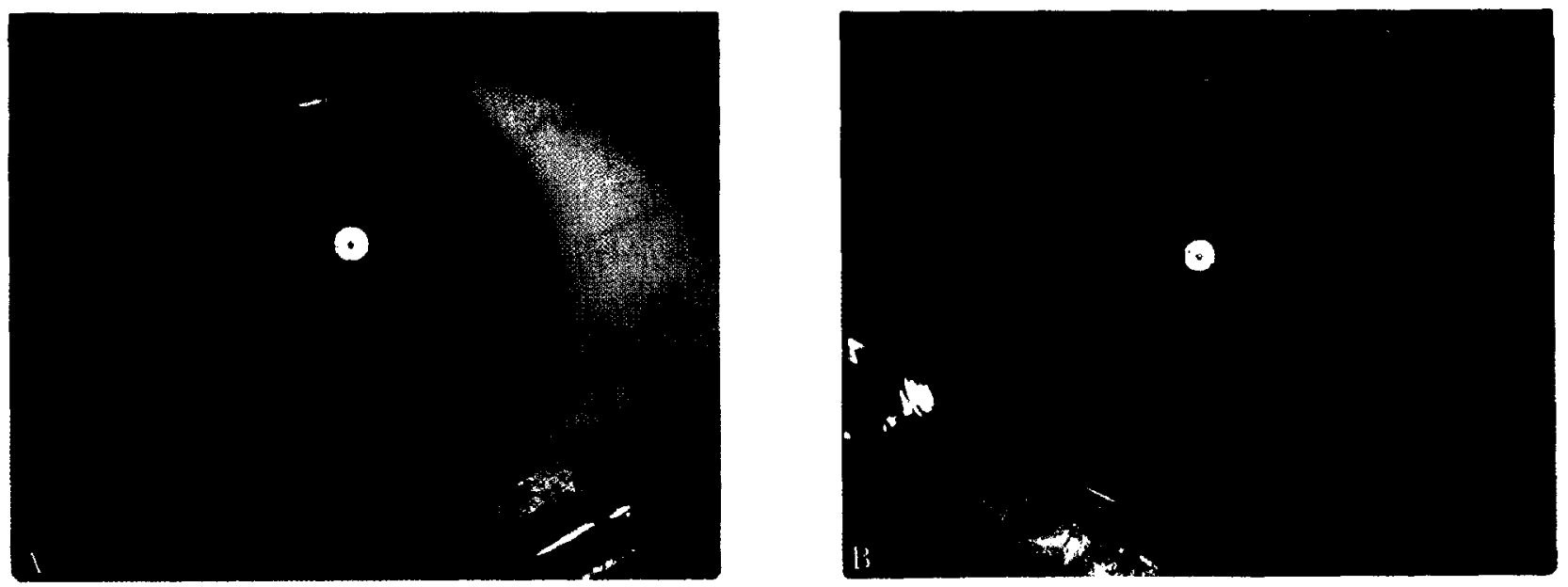

Fig. 1. Acquired heterochrumia. Note lighter blue right eye (A), darker brown left eye (B). Both pupils are pharmacologically dilated.
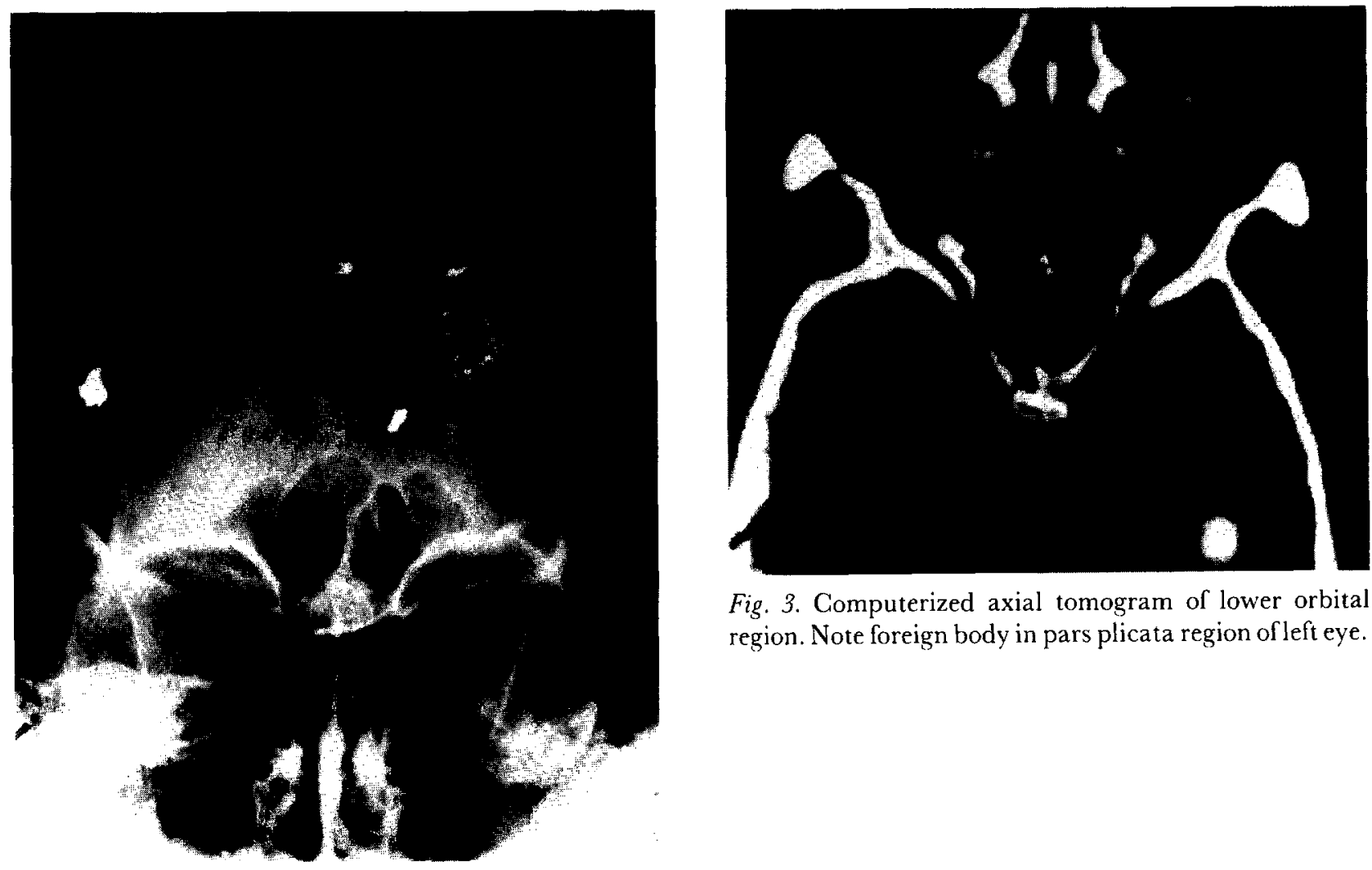

Fig. 3. Computerized axial tomogram of lower orbital region. Note foreign body in pars plicata region of left eye.

Fig. 2. Orbital x-ray. Posterior-anterior view. No metallic density objects are demonstrated in the orbital region. Metallic fragments in the parietal region are the result of previous injury. 
tecting ocular foreign bodies. Recent reports ${ }^{2.1-7}$ have demonstrated the value of computerized axial tomography in the detection of intraocular foreign bodies. Computed tomography is especially helpful in uncooperative patients, multiple foreign bodies, foreign bodies adjacent to the scleral wall, and anterior foreign bodics. CT scanning may be of significant assistance in revealing the relationship of foreign bodies to the coats of the eye. Steel foreign bodies as small as $0.06 \mathrm{~mm}^{2}(0.5 \mathrm{~mm}$ in diameter $)$ can now be detected with modern scanners. ${ }^{\text {hi }}$ Attenuation coeflicients are variable.

Ocular siderosis results from the accumulation of iron ions in intraocular epithelial structures, and often leads to glaucoma and retinal degeneration. $1 . .3$ In this patient, early ocular siderosis was suspected because of the history of prior injury, heterochromia of the iris, and corncal perforation site, but a foreign body could not be found by ophthalmic examination or standard $x$-ray techniques. Computerized axial tomography confirmed the presence of a metallic foreign body and demonstrated its precise location, leading to effective removal. Computerized axial tomography should be used in clinical situations in which the presence of a foreign body is suspected and its precise location must be known. Electroretinographic changes may be of benefit in establishing a diagnosis of ocular siderosis. The electroretinogram in patients with siderosis passes through stages from super-normal to nonrecordable responses. These changes depend upon the composition, degree of encapsulation, size and location of the foreign particle. 'In our patient, the electroretinogram was normal in spite of the presence of heterochromia caused by siderosis.

\section{References}

I. Detercatsis Meredith Ci. Rusenthal AR: Experimental siderosis in the rabbit. Arch ophthalmol 95:1051-1058. 1977

2. Gasier RN. Duda EF: I ocalization of intrancular foreign bodies by computed comogratphy. Ophthatmic furg 11:25-29, 1980)

3. Kinare B: Electroretinngraphy in eycs with retained intraocular forcign bodies. A clinical study. Acta Ophthalmol 100):5-63,1969

1. Kollarits (:R. (hiro Gl). Christiansen J, e't al: Detection of orbital and intraorular forrign budies by computerized tomography. Ophthalmic Surg 8:45-53. 1977

j. Lahes LA, (iratud MG, Reece J. Penkrot RJ: (iomputerized axial tomography in the detection of intraocular foreign bodies. Ophthalmology $88: 26-29,1981$

6. Tate E, Ciupples $\mathbf{H}$ : Ietection of orbital forcign bodics with computed tomography: Current limits. Am / Roentgenol 137:493-49.5. 1981

7. Tosuka K, Takat M: ("l scamner and the reliable limit of detection on intrancular forcign bodies. Nippon Ganka Ciakkai Zasshi 82:388-392. 1978

Reprint refuests shonld be addressed w Charles (: Barr, M.1). Department of (Ophthalmolegg. I'niversity of Lusuisville. School of Medicine. 301 E. Muhammad Vi Boulerard, Louisville. Kenturky 11202 